\title{
RECYCLED BLESSINGS: AN INVESTIGATIVE CASE STUDY OF A RE-WRAPPED EGYPTIAN VOTIVE MUMMY USING NOVEL AND ESTABLISHED 3D IMAGING TECHNIQUES
}

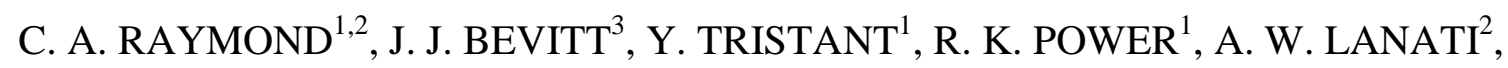
C. J. DAVEY ${ }^{4,5}$, J. S. MAGNUSSEN ${ }^{6}$, and S. M. CLARK ${ }^{2,3}$

${ }^{1}$ Department of Ancient History, Macquarie University, North Ryde, NSW, 2109, Australia;

${ }^{2}$ Department of Earth and Planetary Sciences, Macquarie University, North Ryde, NSW, 2109, Australia; ${ }^{3}$ Australian Centre for Neutron Scattering, Australian Nuclear Science and Technology Organisation, Lucas Heights, NSW, 2234 Australia; ${ }^{4}$ Australian Institute of Archaeology, Macleod, VIC, 3085, Australia; ${ }^{5}$ School of Historical and Philosophical Studies, University of Melbourne, Parkville, VIC, 3010, Australia; ${ }^{6}$ Faculty of Medicine and Health Sciences, Macquarie University, NSW, 2109, Australia.

\begin{abstract}
:
This case study was the first of its kind, where neutron computed tomography (CT) was applied to a wrapped mummified animal. Conventional X-ray CT was also used to allow for meaningful comparison, and complementary data for a comprehensive investigation. This is the author manuscript accepted for publication and has undergone full peer review but has not been through the copyediting, typesetting, pagination and proofreading process, which may lead to differences between this version and the Version of Record. Please cite this article as doi: $10.1111 / \operatorname{arcm} .12477$
\end{abstract}

This article is protected by copyright. All rights reserved. 
Previous applications of both techniques are limited to metallic objects, such as the bronze buddhas (Lehmann et al. 2010). The mummy used in this study (IA.2402) is dated between the Third Intermediate Period (1069-664 BCE) to Late Period (664-332 BCE) according to wrapping style, and was originally believed to contain a complete skeleton of a feline. However, precise date and provenance were unknown. Our results prove the presence of only partial juvenile feline remains, and provide a date range for artefact creation (900-804 BCE $\pm 30)$ and alteration $(367-204 \mathrm{BCE} \pm 30)$. Therefore, this study implements an established imaging technique (neutron CT) in a novel way, while preserving and conserving the intrinsic value of the artefact through non-destructive investigation.

Keywords:

neutron, computed tomography, x-ray, votive offerings, mummification, radiocarbon, ancient Egypt 


\section{INTRODUCTION}

The ancient Egyptians are world-renowned for their practice of mummification of deceased Pharaohs, royalty and nobles. They were also prolific producers of animal mummies, a practice that began during the Old Kingdom Period (2649-2150 BCE) and continued until the beginning of the Islamic Period (642 CE) (Harrell \& Lewan 2002; Maurer et al. 2002; Ikram 2015a). The wrapping design and style changed as a reflection of the period and demand for 'products'. The majority of animal mummies were produced for religious purposes, falling into two subtypes: sacred animals and votive offerings. Sacred animals were considered as the incarnation of a particular god and thus received elaborate burial and mummification (Nicholson et al. 2015). Votive offerings make up the large majority of animal mummies found; votives served as a gift to the gods, an exchange for their favour, or for a blessing such as health, protection or prosperity (Bleiberg et al. 2013; Plessis et al. 2015; Wasef et al. 2015; Nicholson et al. 2015). They were purchased by pilgrims and lower-class Egyptians and offered to a particular god or goddess at the temple. Many different animals were mummified and dedicated to respective deities, for example, dogs to Anubis, ibises to Thoth, and cats to Bastet. Here we focus on mummified cats.

Mummification of cats had reached a peak in popularity between the Late Period (525$332 \mathrm{BCE}$ ) and the end of the Roman Period (30 BCE-395 AD). In order to meet these increased demands for votive offerings, cats were bred en masse at breeding grounds, prior to being killed and mummified (Armitage \& Clutton-Brock, 1981; Malek, 1993; Ejsmond \& Przewlocki, 2014; Zivie \& Lichtenberg, 2015). Once votives were dedicated at the temple, they were buried in designated catacombs and cat burial grounds, for example, Abydos, 
Bubastis, Dendara, Hierakonpolis, Mostagedda, Saqqara, Speos Artemidos near Beni Hassan, and Tanis (Malek 1993; Ejsmond \& Przewlocki 2014; Ikram 2015a). Votive offerings have been found in great numbers and variety at these sites, often differentiated by historical periods.

As a result of their popularity, the increased demand for votive offerings put a stress on the production system, evidenced by a lower quality of wrappings and an increased occurrence of partial and incomplete skeletal remains. These partial and 'fake' mummies became very common, featuring odd combinations of a head, a limb, or tail, multiple animal skeletons or that of an entirely different animal to that represented in the wrapping (Brier 2001; Malgora et al. 2011; Bleiberg et al. 2013; Ikram 2015), or even plant matter and mud with no trace of animal remains (Cornelius et al. 2012). It is uncertain if this was a concern for pilgrims or Egyptians purchasing votive offerings, as the offerings were never intended to be unwrapped. This raises questions concerning the sanctity of the object when it is not an entire animal.

As the mummification process is not well documented, neither in written nor epigraphical form, there are a lot of questions surrounding how it was undertaken. A small collection of illustrations in Egyptian art depict aspects of the mummification procedure, such as those found in tomb paintings near Thebes and Giza. These reveal small details of ceremonial wrapping, spells and rituals performed during mummification (Theban Tombs of Thay: TT23 and TT41) (Ikram 2011). Additional scenes of mummification have been found on the coffin of Djedbasteriufakh at el-Hibeh (Carruthers 2017). Herodotus ( $5^{\text {th }}$ century BCE) 
and Porphyry $\left(3^{\text {rd }}\right.$ century CE) discuss mummification processes, providing the most comprehensive and detailed contemporary account. Consequently, the process for animal mummification was not well understood until more recently, when people started unwrapping the bundles. Mummy unwrapping parties were popular within affluent Victorian society, as a source of entertainment, and out of curiosity rather than for educational research (David, 1997; Smith, 2016). Many mummies were damaged or destroyed entirely in the wake of these deleterious practices. Destruction also occurred during scientific investigations, which intended to provide insight into the wrapping techniques and patterns. By unwrapping mummified cats retrieved from the Bubasteion (cat cemetery at Bubastis) much was discovered about the variety of cat species, number of layers of textile, tightness and corkscrew style of internal wrapping, and average length of the bandages (Ginsburg 1999). While such investigations provided a lot of valuable insight into the mummification process, this should not be seen as affirmation of destructive practice, rather this illustrates and emphasises the need for less-destructive or non-destructive practice.

The discovery of X-rays in 1895 by W. Röntgen (Röntgen 1896; Janssens \& Van Grieken 2004) provided a new means of examination for the contents of mummies that was not harmful to the artefacts. The first documented experiment using X-ray 2D radiography on Egyptian mummified remains was in 1896, by Konïg and Thurston Holland (David 1997). Computed tomography (CT) was introduced to the scientific community in 1972, and the first commercial CT scanner (the EMI CT 1000) became available in late 1973 (Cierniak 2011). X-ray CT was first utilised in mummy investigations in 1979 by Canadian (Harwood-Nash 1979) and British scientists (Isherwood et al. 1979), and Dutch scientists in 1981 (Raven \& 
Taconis 2005); X-ray CT has since become a routine method of examination. The Manchester Mummy project has been instrumental in imaging 280 mummified animals over 12 years (2000-2012) using radiology facilities at the various hospitals across the city (Adams 2015). Using X-ray CT to verify the contents and authenticity of the mummy has previously revealed potential causes of death such as breaks, fractures or significant injury to the skeleton, and epiphyses, which can inform age of animal at death.

Conversely, neutron tomography is a relatively novel imaging technique when compared to X-ray and computed tomography (CT) in archaeological investigations. It is a 3D imaging technique that uses neutron attenuation to reveal the internal structures or contents of an object. When comparing these techniques, it is important to understand the fundamental principles of each. X-ray studies rely on the relative attenuation of an X-ray from a source due to its interactions predominantly with the electrons of the item being examined. However, neutron studies utilise an interaction of neutrons within the nucleus' of the atoms in the sample. This means that although both techniques require a source, the particles involved, and therefore how they behave, are very different. While both techniques are attenuated effectively by dense materials, the attenuation of neutrons is not correlated with atomic mass, unlike X-rays. Neutrons were first discovered by James Chadwick in 1932. Following shortly after, neutron radiography was developed by Kallman and Peter in the late 1930s, with publication delayed until after the Second World War (Heller \& Brenziner 2009; Nguyen 2011). Neutron radiography offers complementary information to X-ray radiography, particularly where high-density, object size, or the presence of metals prevents structural study with X-rays. To date, there are no published accounts demonstrating the application of 
neutron radiography (or neutron $\mathrm{CT}$ ) to wrapped mummified remains, there is one case of neutron tomography performed on an unwrapped mummified child's head (Salvemini et al. 2016).

As the technique is relatively novel, it is surrounded by a several concerns. Primarily, neutron CT requires access to a neutron source, and these are both limited in number and can be difficult to access. According to the International Society of Neutron Radiology, there are only 13 operational neutron CT instruments worldwide, and an additional three that are built but not currently available (Bücherl 2017). Additionally, as this is a nuclear method, it requires the sample to be irradiated for a short period of time. The ionising dose to which samples are exposed is not well known, nor documented to date, thus their impacts on cellular degradation of ancient biological material are unknown. Furthermore, neutron irradiation results in neutron activation, and temporary residual radioactivity of the object. Depending on the energy and intensity of the neutrons used, and composition of the samples studied, the artefact may remain radioactive for periods of time between hours and years (Bettuzzi et al. 2015).

An excellent illustrative example of a combined X-ray and neutron CT study was undertaken in 2010 on a small selection of bronze Buddhas from Tibet (Lehmann et al. 2010); the statuettes were scanned using both imaging techniques, yielding useful and complementary data. Both techniques have the capacity to non-invasively study these objects. This allows protection of their intrinsic and religious value, while permitting a validation of authenticity, which is important to the ethnic group to which the artefacts pertain. The 
application of these techniques to mummified remains permits investigation of the textile layers, and the process in which the mummy was wrapped. Furthermore, neutrons may provide more information about any remaining soft tissue or hydrogenous materials within the wrapping, without physically unwrapping or destroying the sample. In order to explore the potential benefits of combining x-ray and neutron tomography for the study of mummies we have undertaken a study of a cat mummy using these two techniques.

\section{A VOTIVE OFFERING}

The cat mummy investigated in this study is in the collection of the Australian Institute of Archaeology, Melbourne, Australia (Reg. No. IA1.2402). It was brought to Australia without record of provenance by Sir Charles Nicholson after he visited Egypt in 1856-7 and it is listed as No 30 in Agyptiaca (Nicholson 1891). The hypothesis for this mummified specimen, is that it was made sometime between the Late Period and the Roman Period. This was determined after a detailed observation of the specimen and identification of mummified specimens of similar style and features. This hypothesis was addressed through radiocarbon dating, as well as by investigating changes in wrapping typology and morphology over time.

The mummy measures $21.29 \mathrm{~cm}$ from the tip of its ears to the base, $4.79 \mathrm{~cm}$ in width, and $7.82 \mathrm{~cm}$ in depth. It is an unusual sample, in that it has very unique painted details across the entirety of the wrapping. No other samples to date have been found with all these markings (Figure 1). Three paint colours can be easily identified, being red, green and black. There is also a dark brown resinous substance, suspected to act as a gluing agent to secure 
fabric ends. It is in overall good condition, with a few areas where the textile is fraying. It has an opening in the base that measures $8 \mathrm{~mm}$ wide and $21.5 \mathrm{~mm}$ long, running from the right posterior to anterior. Fur and skin of the encased animal can be seen through this hole in the base. This was the location of sample collection for radiocarbon dating, prior to neutron and X-ray CT scanning.

\section{METHOD}

The mummy was X-ray CT scanned using a Newtom 5G (Newtom, Italy) cone-beam computed tomography (CBCT) scanner, and a GE HD750 (General Electric, Milwaukee, USA) multi-detector (MDCT) and dual-energy (DECT) capable scanner, located at Macquarie Medical Imaging (Macquarie University Hospital, Sydney, Australia). All scans were performed by Professor John Magnussen and his team. The sample was placed on its right lateral side and propped up on a low-density polyethylene foam block to provide some protection and to position it more ideally for data acquisition. The specimen was then loaded head-first into the scanner, first the Newtom 5G, then the GE HD750. Data acquisition took a matter of seconds per scan, allowing for a total of six scans to be acquired: three CBCT, two MDCT, and one DECT (Figure 2a). The data were analysed using InteleViewer 4-11-1-P130 and reconstructed in 3D using RadiAnt DICOM Viewer 3.4.2.

The mummy was neutron-CT scanned using the DINGO neutron-imaging facility (Figure 3a-b), located on the thermal HB 2 beam, tangentially facing the 20 MW Open-Pool Australian Lightwater (OPAL) reactor housed at the Australian Nuclear Science and Technology Organisation (ANSTO), in Sydney, Australia (Garbe et al. 2015). The sample 
required no preparation for this process, however it was wrapped in aluminium foil, which is invisible to neutrons, to position it vertically and to provide a degree of physical protection while on the instrument's sample stage. As the long-term impacts of neutron irradiation of ancient mummified remains is currently unknown, the neutron CT scan parameters were chosen to reduce the total length of exposure of the specimen to neutrons, thus to minimising the potential for radioactivation, cellular ionisation and potential degradation of ancient DNA. It is important to note that thermal neutron irradiation over the length of the measurement was calculated to have no measurable impact on the ${ }^{12} \mathrm{C}:{ }^{14} \mathrm{C}$ ratio via neutron capture and transmutation, and thus no measurable impact on apparent radiocarbon age.

The DINGO facility utilises a quasi-parallel collimated beam of thermal neutrons from OPAL with a maximum spectrum intensity at $1.08 \AA(70 \mathrm{meV})$ and full-width-at-halfmaximum (FWHM) of $0.9 \AA(100 \mathrm{meV})$. For this study, a collimation ratio $(L / D)$ of 1000 was used to ensure highest available spatial resolution, where $L$ is the neutron aperture-tosample length and $D$ is the neutron aperture diameter(Garbe et al. 2011; Garbe et al. 2015). The field of view was set to $200 \times 200 \mathrm{~mm}^{2}$ and a voxel size of $95.5 \times 95.5 \times 95.5 \mu \mathrm{m}$. Neutrons were converted to photons with a $200 \times 2000.100 \mathrm{~mm} \mathrm{ZnS}(\mathrm{Ag}) /{ }^{6} \mathrm{LiF}$ scintillator screen (RC Tritec AG); and resultant photons were then detected by an Andor IKON-L CCD camera (liquid cooled, 16-bit, $2048 \times 2048$ pixels) coupled with a Makro Planar $50 \mathrm{~mm}$ Carl Zeiss lens. A total of ten white field (open shutter) and dark field (closed shutter) images were collected prior to scanning the mummy. These are needed for normalisation of radiographs during the reconstruction process. A total of 720 equally-spaced radiographic projections were obtained every $0.25^{\circ}$ as the sample was rotated $180^{\circ}$ about its vertical axis, 
according to the parameters specified in Figure $2 \mathrm{~b}$. The raw images were de-noised using the software package Image $\mathbf{J}(\mathrm{NIH})$, and tomographic reconstruction of the 16-bit raw data was performed using Octopus 8.2 (Octopus Imaging) and a filtered back-projection algorithm. The reconstructed volume data were rendered and visualised using VG Studio Max 3.0 (Volume Graphics GmbH).

Upon completion of the neutron $\mathrm{CT}$ scan, the radioactivity of the specimen was measured as $26 \mu \mathrm{Sv} / \mathrm{h}$ using a Canberra Radiagem ${ }^{\mathrm{TM}} 2000$ Portable Dose Rate and Survey Meter. After $24 \mathrm{hrs}$ the radioactivity of the sample had dropped to $1.5 \mu \mathrm{Sv} / \mathrm{h}$ and was not detectable 3 days after the exposure. At this point, a radiological clearance certificate was obtained, providing formal approval for the release of the specimen from the neutronscattering laboratory, and for the return of the specimen to the Australian Institute of Archaeology.

A small portion of barely-attached wrapping was carefully isolated and removed from the mummy, along with fragmentary material that had previously fallen off the specimen, and a sample of fur was extracted through an opening in the wrappings located at the base of the mummy. These two samples were weighed and placed in separate vials; the fur sample weighed $11.2 \mathrm{mg}$, while textile sample weighed $3.0 \mathrm{mg}$. These were then sent to Beta Analytic Inc., in Miami, Florida for radiocarbon dating. The method of analysis they undertook is as follows: the two samples were washed with hot $\mathrm{HCl}$ acid and then $\mathrm{NaOH}$ alkali wash to remove secondary organic acids. A final acid rinse was then used to neutralise the materials before drying. Following these treatments, the samples were reduced to graphite 
(100\%), and then analysed for carbon 14 content in an Accelerator Mass Spectrometer

(AMS). The results were corrected for isotopic fractionation and converted into a calendarcalibrated date. It is important to note that samples collected from the artefact were kept to the smallest possible size to limit artefact damage as radiocarbon dating is a destructive analysis technique.

\section{RESULTS}

The X-ray data, once reconstructed, revealed a partial skeleton, with a high density contrast between textile and bone (Figure 4). There is a clear difference between the inner and outer layers in the X-ray data, showing higher density in the inner wrapping. The direction of wrapping is not discernible by these data, neither is the coarseness of the textile. X-ray CT showed strengths for identifying metallic materials within, and on, the wrappings. Most notably, X-ray CT reconstructions revealed a small high X-ray attenuating artefact, likely made from a heavy metal, close to the paws of the cat, seen in Figure 4d. Thin, irregular layers of very highly attenuating areas are confined to the outermost wrapping of the mummy (Figure 4a and 4d). Visual inspection of the specimen shows a correlation between these regions with the green painted markings on the outermost bandages. Where the green paint is on the wrapping appears much brighter than the red. This means there is a high attenuation of X-rays, implying the paint contains a compound containing one or more heavy elements. This observation will be expanded upon in a later contribution by our group.

The neutron data, once reconstructed, revealed areas of 'padding' and layers of textile (Figure 4b-d). These reconstructions show two different textile layers according to their 
density, possibly due to varying coarseness of the textile or tightness of wrapping around the bones. The inner-most wrapping is brighter and more densely wrapped than the outer. The outer layers appear to have considerably more space between the layers than the inner textile. In the upper section of the specimen, the bones appear securely wrapped, with extra textile above, containing no objects. The folded textile appears to be solely for the purpose of creating the shape of a skull. The lower section of the specimen is less padded, with little to no textile around the base where the opening is located. As a result, the remains of the animal are poorly secured in the lower section, and more prone to mobility. There is also a thick, bright outline that is not associated with the wrappings; within this outline is a dark, void-like space, in which the bones sit (Figure 4b). This bright outline signifies a more dense or hydrous material, such as the skin of the animal. The neutron CT data did not clearly show the presence of the small metallic artefact, previously seen in X-ray data (Figure 4d). The bones visible in the X-ray and neutron CT images include a femur, two fibulae, one tibia, two sets of metatarsals and phalanges complete with claws, and an articulated tail with 23 vertebrae.

Prior to radiocarbon analysis, the fur sample was re-categorised as 'plant material' by Beta Analytic, as there was a large amount of plant material present. Following Accelerator Mass Spectrometry (AMS) dating, the results showed that the mummified remains, mixed with plant material were $2690 \pm 30 \mathrm{BP}$ (before present), placing it between $900-804 \mathrm{BCE}$ to $95.4 \%$ confidence. The external wrapping sample is approximately 500 years younger than the encased remains, dating to $2230 \pm 30 \mathrm{BP}$ (367-204 BCE), between the Late Period and Ptolemaic Period. 


\section{DISCUSSION:}

X-ray and neutron 3D visualisations allowed non-destructive imaging of the internal contents of the specimen. This provided an opportunity to better determine the species, age, sex and health status and preservation of the mummified animal. The presence of these hind limbs, coccygeal and caudal vertebrae indicated that this mummified specimen is the rear of a small mammalian digitigrade.

The tail has been broken, most likely post-mortem. The remains are extremely decayed, and it is difficult to determine the presence of some coccygeal and caudal vertebrae, however there were approximately 23 present. This indicates that it is most probably a Felid, as they typically have 19-23 caudal vertebrae. This inference is supported by the morphology of the components of the skeleton, which are consistent with that of genus Felis (T. Fothergill, personal communication, 24 May 2017). It is therefore concluded, based on these observations, that the animal encased in the wrappings is a feline.

The age of the animal at the time of death can be determined by observing the growth plates (epiphyses) between bones. The reconstructed neutron data revealed that there was partial-fusion of bones in the left hindlimb. Based on the authors understanding of the contributions by Habermehl (1985) and Van Neer et al. (2014), the state of the epiphyses between the distal metatarsals, proximal tibia and distal femur indicate that the animal had not yet reached adulthood when it died. The state of the epiphyses depends on whether the animal was domesticated or from the wild. Typically, wild animals experience fusion of growth plates at a later stage, near to or following one year of age (Habermehl 1985; Van 
Neer et al. 2014); domesticated animals tend to experience this earlier (Habermehl, 1980; Van Neer et al., 2014). In the absence of other skeletal elements, it is not possible to corroborate the evidence for breeding status of this animal as either wild or domesticated. At this stage, best estimates for the age of the mummified animal is a juvenile or subadult cat, younger than 11.5 months old (T. Fothergill, personal communication, 24 May 2017).

Classifying the species based on visible features in the CT data is difficult due to the juvenile nature of the cat, and absence of many key features that would hint to the species, such as skull shape and size, as discussed by Johansson et al. (2015). An additional indicator of species type is based on tail length, as longer tails $(320 \mathrm{~mm})$ are characteristic of Felis silvestris, and shorter tails (250 mm), Felis chaus (Johansson et al., 2015). However, the lengths recorded by Johansson et al. (2015) are those of adult cats, and this case study is not in the same category, as previously established. The length of the tail of this mummy is approximately $126 \mathrm{~mm}$, falling short of their parameters for either species.

The shape and size of the calcaneus is also characteristic of particular species. These bones are present in the left limb more clearly than in the right. While the 3D reconstruction of the X-ray data shows that they are extremely decayed, the bone was manually segmented, using VG studio, to reveal a definitive shape (Figure 4d). Comparing the shape and size of the bone with that mentioned in Van Neer et al., (2014) for mummified adult cat skeletons, there is a clearer resemblance to the calcaneus of Felis silvestris than that of Felis chaus (Figure 4c). The shape of the calcaneus was also examined to indicate sex (Van Neer et al. 2014), which could potentially be closer to that of the female of the species, due to the wider 
flare of the socket, however, due to the age of the animal, it is difficult to confirm. Additionally, there is no baculum (penis bone) found within the wrappings, which could suggest that the cat was female, or that this bone was for some reason not included, as there is no pelvis in the wrappings either. There are no clear signs of inflicted trauma on the legs and tail that may have killed the animal. Often animals received a sharp blow to the head, or twisting and snapping of the neck (Armitage \& Clutton-Brock 1981; Ejsmond \& Przewlocki 2014; Johansson et al. 2015; Zivie \& Lichtenberg 2015) when they were harvested. In this case, it is not possible to identify these features due to the incompleteness of the remains, so no indication of the cause of death can be established. Overall, the evidence presented above shows that this animal is a female juvenile cat of the species Felis silvestris.

\section{Radiocarbon dating}

Knowing that the mummified cat remains are approximately 500 years older than the bandages that surround them leads us to suggest that the animal remains were re-wrapped at the end of the Late period (664-332 BCE). This poses several questions: what was the original state of the remains and were they partial or a whole skeleton? There are two possible scenarios: the first being that the remains were originally a complete feline skeleton, or the second, that the original state was as it is now, a partial skeleton. If the animal had originally been wrapped as a complete feline skeleton in the Third Intermediate Period, and was divided in the Late Period, post mortem, there would be evidence that the animal had been broken apart, i.e. damage to hard and/or soft tissue, fractured bones or jagged edges on bones. Examining the X-ray and neutron CT data, no signs of post-mortem trauma or damage 
are visible. The end of the femur does not exhibit evidence of jagged breaking (Figure 5), and no evidence of soft tissue trauma. Aside from the broken tail, there does not appear to be any sign of post-mortem forceful manipulation of the skeleton. Additionally, the epiphyses are still intact, which suggests that there has been no direct post-mortem interference with the remains. The remains would have been very fragile after 500 years, and prone to breaking or disarticulating with excessive handling or interference. It therefore seems that the legs and tail of this mummy are the original remains, and were re-wrapped in the Late - Ptolemaic period. As previously mentioned, this was a time of high demand for mummified votive offerings at temples, and the manufacturers and embalmers were struggling to keep up with this demand (Kurushima et al. 2012; Ejsmond \& Przewlocki 2014; Petaros et al. 2015). When the mummy was first made, Egypt's capital would have been either Tanis or Bubastis in the Nile Delta (900-800 BCE), in both cities there are major votive animal cemeteries dedicated to cats (Zivie \& Lichtenberg 2015; Ikram 2015a). However, 500 years later at the end of the Late period, and Egypt's capital had been relocated to Sebenytos (380-343 BCE), then Alexandria from 332 BCE until 641 CE (Lloyd 2000a; Lloyd 2000b), closer to these older burial grounds. It is possible that the old catacombs of these animal cemeteries may have been pillaged like many tombs were around this time, for the amulets and grave goods they contained (Nicholson et al. 2015) This would mean that the disturbed remains may then have been re-wrapped and re-sold. By re-wrapping the mummies in new bandages, they are made to appear new, and pilgrims wanting to purchase votive offerings at the temple would not have known the difference.

\section{Comparison of the techniques}


Both neutron and X-ray CT proved useful in studying the skeleton inside the wrappings. X-ray CT, due to higher X-ray attenuation for bone and metal, produced better radiographs of the skeleton (Figure 4) than neutron CT, which is more greatly attenuated by hydrogenous and organic materials. As this sample is almost entirely organic, there was little contrast between bones and wrapping in the neutron CT (Figure 4), compared to the high-density contrast seen in X-ray CT radiographs. Despite this, both techniques showed epiphyses between bones, which was ultimately helpful for identifying the age of the cat at its death (Figure 6).

As individual techniques, neutron and X-ray CT have their strengths and weaknesses. In some cases one addresses the limitations of the other. Here we have demonstrated the synergies of the techniques, and how they can be combined to give a comprehensive study of mummification processes (Figure 6c). 3D reconstruction of the collected data from both Xray and neutron $\mathrm{CT}$ allowed for an unprecedented view of the internal wrapping, layers and contents of the mummy. Both techniques revealed a partial skeleton, which, through detailed analysis and examination allowed for identification of the age at death, species, and sex of the remains. These techniques separately addressed some of the main objectives of this study, however as a pair, they presented a complete and comprehensive view of the mummified animal (Figure 5c). Imaging studies were non-destructive to the remains, and successfully illustrated their respective strengths and weaknesses.

CONCLUSION: 
A primary aim of this project was to assess the usefulness of neutron tomography as a routine technique in archaeometry. The high resolution, high contrast, three dimensional images that we obtained by using these two techniques allowed the determination of a myriad of details for both, the mummy and wrappings. These include the discovery of a partial cat skeleton, the age at death and species of the cat, the presence of a concealed metallic object and details of two types of wrappings. Additionally, the acquisition of radiocarbon dates has allowed us to place the initial remains and the re-wrapping within the context of Egyptian history. This highlighted the discrepancy between the ages of the remains and the wrappings, providing a first-hand example of how artefacts and mummified bundles were re-used to meet the increased demands for votive offerings in the Late Period - Ptolemaic period. This difference in ages prompted the investigation into how remains from the Third Intermediate Period were obtained and re-wrapped in the Ptolemaic Period. Since the acquisition of the data used here, advances in neutron CT data collection made at ANSTO now make it possible to image the inner wrapping at higher resolution and potentially digitally unwrap the cat (Bevitt, J., personal communication, 3 September 2017). Finally, this pilot study demonstrates the power of combining these techniques for archaeometric studies and marks a new phase of our ability to non-destructively analyse ancient relics and inform us of the cultures and practices of ancient societies.

\section{Acknowledgements}

The authors thankfully acknowledge the assistance of Tyr Fothergill for her contribution to the understanding of the skeletal remains. Further thanks to the Macquarie 
Medical Imaging team for their time and enthusiasm in scanning the mummy. C. A. Raymond was supported by an Australian Government Research Training Program (RTP) Stipend and RTP Fee-Offset Scholarship through Macquarie University, and Macquarie HDR funds; this work formed part of a Master of Research thesis submitted to Macquarie University. The authors also acknowledge the assistance of ANSTO and MMI for scanning and beam time costs. We recognise the volume of care and effort taken by reviewers to evaluate works for publication and gratefully acknowledge the comprehensive, and constructive, reviews provided by our three anonymous reviewers that have increased the quality and clarity of this contribution. 
References:

Adams, J., 2015. Imaging animal mummies: history and techniques. In Gifts for the Gods: ancient Egyptian animal mummies and the British. pp. 68-71.

Armitage, P.L. \& Clutton-Brock, J., 1981. A Radiological and Histological Investigation into the Mummification of Cats from Ancient Egypt. Journal of Archaeological Science, 8, pp.185-196.

Bettuzzi, M. et al., 2015. Computed tomography of a medium size Roman bronze statue of Cupid. Applied Physics A: Materials Science and Processing, 118(4), pp.1161-1169.

Bleiberg, E., Barbash, Y. \& Bruno, L., 2013. Soulful Creatures: Animal Mummies in Ancient Egypt, Brooklyn: GILES.

Brier, B., 2001. Case of the Dummy Mummy. Archaeology, 54(5), pp.28-29.

Bücherl, T., 2017. User facilities. International Society of Neutron Radiology (ISNR).

Carruthers, J., 2017. Unwrapping Mummification Techniques in Ancient Egypt. In Y. Tristant \& E. M. Ryan, eds. Death is Only the Beginning. Oxford: Aris and Phillips Ltd., pp. 88-99.

Cierniak, R., 2011. Some words about the history of computed tomography. In X-Ray Computed Tomography in Biomedical Engineering. pp. 1-319.

Cornelius, I. et al., 2012. Looking inside votive creatures: computed tomography (CT)

This article is protected by copyright. All rights reserved. 
scanning of ancient Egyptian mummified animals in Iziko museums of South Africa: A preliminary report. Akroterion, 57, pp.129-148.

David, A., 1997. Disease in Egyptian mummies

Thethe contribution Lancet, 349, pp.1760-63.

Ejsmond, W. \& Przewlocki, L., 2014. Some Remarks on Cat Mummies in Light of the Examination of Artefacts From the National Museum in Warsaw Collection J. Debowska-Ludwin, M. A. Jucha, \& P. Kolodziejczyk, eds. Studies in Ancient Art and Civilisation, 18, pp.239-258.

Garbe, U. et al., 2015. A New Neutron Radiography / Tomography / Imaging Station DINGO at OPAL. Physics Procedia, 69(October 2014), pp.27-32.

Garbe, U., Randall, T. \& Hughes, C., 2011. The new neutron radiography/tomography/imaging station DINGO at OPAL. Nuclear Instruments and Methods in Physics Research, Section A: Accelerators, Spectrometers, Detectors and Associated Equipment, 651(1), pp.42-46.

Ginsburg, L., 1999. Les chats momifiés de Bubasteion de Saqqarah. Annales du Service des Antiquités de l'Égypte, 74, pp.183-191.

Habermehl, K.H., 1980. Altersbestimmung bei Versuchstieren, Berlin \& Hamburg: Verlag Paul Parey.

Habermehl, K.H., 1985. Altersbestimmung bei Wild- und Pelztieren, Berlin \& Hamburg:

This article is protected by copyright. All rights reserved. 
Verlag Paul Parey.

Harrell, J.A. \& Lewan, M.D., 2002. Sources of Mummy Bitumen in Ancient Egypt and Palestine. Archaeometry, 44(2), pp.285-293.

Harwood-Nash, D.C.., 1979. Computed Tomography of Ancient Egyptian Mummies. Journal of Computer Assisted Tomography, 3, pp.768-773.

Heller, A.K. \& Brenziner, J.S., 2009. Neutron Radiography. In I. S. Anderson, R. L. McGreevy, \& H. Bilheux, eds. Neutron Imaging and Applications: A Reference for the Imaging Community. New York: Springer.

Ikram, S., 2015a. Divine Creatures, Cairo: AUC Press.

Ikram, S., 2011. Experimental Archaeology: From Meadow To Em-Baa-Lming Table. In C. Grave-Browns, ed. Experiment and Experience. Cardiff: University of Wales Press, pp. $53-74$.

Ikram, S., 2015b. Protecting Pets and Cleaning Crocodiles. The Animal Mummy Project. In Divine Creatures: Animal Mummies in Ancient Egypt. Cairo: The American University in Cairo Press, pp. 207-227.

Isherwood, I., Jarvis, H. \& Fawcitt, R.., 1979. Radiology of the Manchester mummies. In A.R.David(ed),The Manchester Mummy Project: Multidisciplinary Research on Ancient Egyptian Mummified Remains. pp. 25-64.

Janssens, K. \& Van Grieken, R., 2004. Non-destructive Micro Analysis of Cultural Heritage 
Materials, Antwerp: Wilson and Wilson.

Johansson, C., Metz, G. \& Ulhorn, M., 2015. Feline Descendant of the Red or the Black land: A Multidisciplinary Investigation of an Unusually Large Ancient Egyptian Cat Mummy. In Egyptian Bioarchaeology. pp. 177-200.

Kurushima, J.D. et al., 2012. Cats of the pharaohs parigemetic Egyptian cat mummies to their feline contemporaries. Journal of Archaeological Science, 39(10), pp.3217-3223.

Lehmann, E.H., Hartmann, S. \& Speidel, M.O., 2010. Investigation of the content of ancient Tibetan metallic Buddha statues by means of neutron imaging methods. Archaeometry, 52(3), pp.416-428.

Lloyd, A.B., 2000a. The Late Period. In I. Shaw, ed. The Oxford History of Ancient Egypt. Oxford: Oxford University Press, pp. 364-387.

Lloyd, A.B., 2000b. The Ptolemaic Period. In I. Shaw, ed. The Oxford History of Ancient Egypt. Oxford: Oxford University Press, pp. 388-413.

Malek, J., 1993. The Cat in Ancient Egypt, London: British Museum Press.

Malgora, S. et al., 2011. Investigation of the Trento Cat Mummy. Journal of Biological Research, 84(1), pp.354-358.

Maurer, J., Mohring, T. \& Rullkötter, J., 2002. Plant Lipids and Fossil Hydrocarbons in Embalming Material of Roman Period Mummies from the Dakhleh Oasis, Western 
Desert, Egypt. Journal of Archaeological Science, 29, pp.751-762.

Van Neer, W. et al., 2014. More evidence for cat taming at the Predynastic elite cemetery of Hierakonpolis (Upper Egypt). Journal of Archaeological Science, 45(1), pp.103-111.

Nguyen, H.-Y., 2011. Computed Tomography for the Non-Destructive Imaging of Cultural Heritage: X-Ray, Gamma and Neutron Sources.

Nicholson, C., 1891. AEgyptiaca

$\square$ : comprising

in the years 1856, 1857, and now deposited in the museum of the University of Sydney together with an account of some remains of the "disk worshippers" funereal hier, London: Harrison and Sons.

Nicholson, P.T., Ikram, S. \& Mills, S., 2015. The Catacombs of Anubis at North Saqqara. Antiquity, 89(345), pp.645-661.

Petaros, A. et al., 2015. Mummified remains from the Archaeological Museum in Zagreb, Croatia - Reviewing peculiarities and limitations of human and non-human radiological identification and analysis in mummified remains. Journal of Forensic and Legal Medicine, 35(2015), pp.54-61.

Plessis, A. Du et al., 2015. Three-dimensional model of an ancient Egyptian falcon mummy skeleton. Rapid Prototyping Journal, 21(4), pp.368-372.

Raven, M.J. \& Taconis, W.K., 2005. Egyptian Mummies: Radiological Atlas of the Collections in the National Museum of Antiques at Leiden, Leiden: Brespol.

This article is protected by copyright. All rights reserved. 
Röntgen, W.C., 1896. On a New Kind of Rays. Science, 3(59), pp.227-231.

Salvemini, F. et al., 2016. DINGO - the neutron imaging station at ANSTO: embracing material science, palaeontology, and cultural heritage. Neutron News, 27(2).

Smith, S.T., 2016. Unwrapping the Mummy: Hollywood Fantasies, Egyptian Realities. In J. M. Schablitsky, ed. Box Office Archaeology: Refining Hollywood's Portrayals of the Past. Routledge, p. 256.

Zivie, A. \& Lichtenberg, R., 2015. The Cats of the Goddess Bastet. In S. Ikram, ed. Divine Creatures: Animal Mummies in Ancient Egypt. Cairo: American University in Cairo Press, pp. 106-119.

Figure captions:

Figure 1: Mummified cat IA.2402; a-d) Photographs of mummified cat (using $360^{\circ}$ photogrammetry);

The sketches (e-h) show markings on mummified cat wrappings. Bolder lines mark red pigment, and thinner lines mark green pigment. Sketches by C. Raymond.

Figure 2: Method parameters; a) X-ray CT parameters for CBCT, MDCT and DECT; b) DINGO Neutron Tomography parameters.

This article is protected by copyright. All rights reserved. 
Figure 3: a) Setup for DINGO imaging station at ANSTO, as configured for neutron tomography studies (Adapted from Garbe et al 2015); b) Internal layout of the CCD used on the DINGO imaging station at ANSTO (Adapted from Garbe et al 2015).

Figure 4: Results of CT scans (X-ray scans are on the left and neutron scans appear on the right of each pair); a) External comparison of wrapping and painted markings; b) Sagittal slice through the mummy; c) Coronal slice through the cat mummy; d) Transverse slice through the mummy near the paws, showing a highly attenuating object in the X-ray slice, however not in the neutron slice.

Figure 5: Comparison of neutron and X-ray CT scans showing shape of bone, aiding in speciation of encased animal.

a) Cross-section of neutron CT reconstruction, red arrow indicates calcaneus; b) Cross-section of X-ray CT reconstruction, with red arrow and box indicating position of calcaneus; c) Shapes of calcaneus in adult cats (Van Neer et al., 2014); d) Calcaneus extracted manually from X-ray CT data using VG Studio.

Figure 6: Illustration of the power of combined data. a) Neutron CT cross section; b) X-ray CT cross section; c) Combined neutron and X-ray CT data. Yellow arrows indicate areas of epiphyses. 

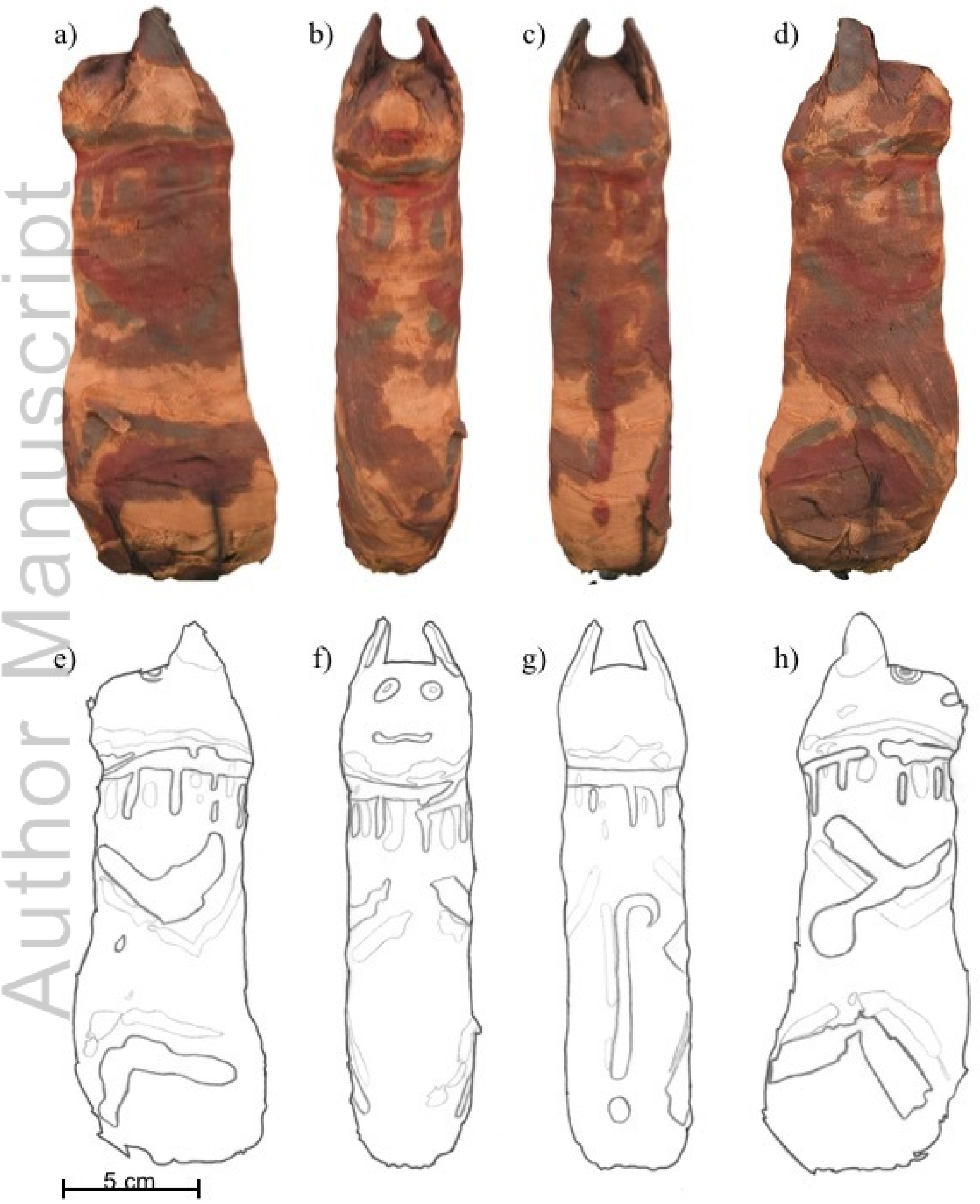

ARCM_12477_Figure_1.jpg

This article is protected by copyright. All rights reserved. 

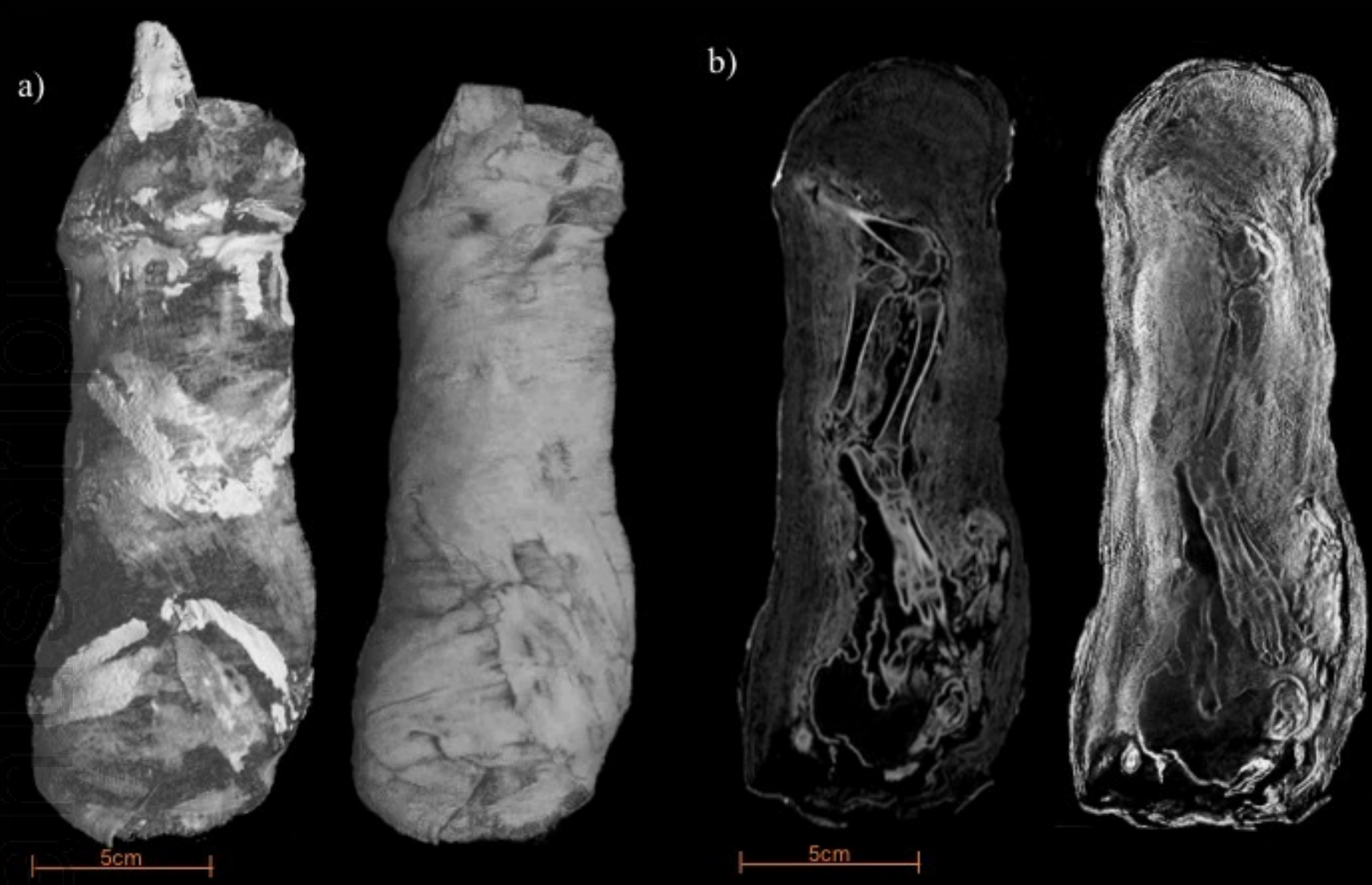

c) $4=1$

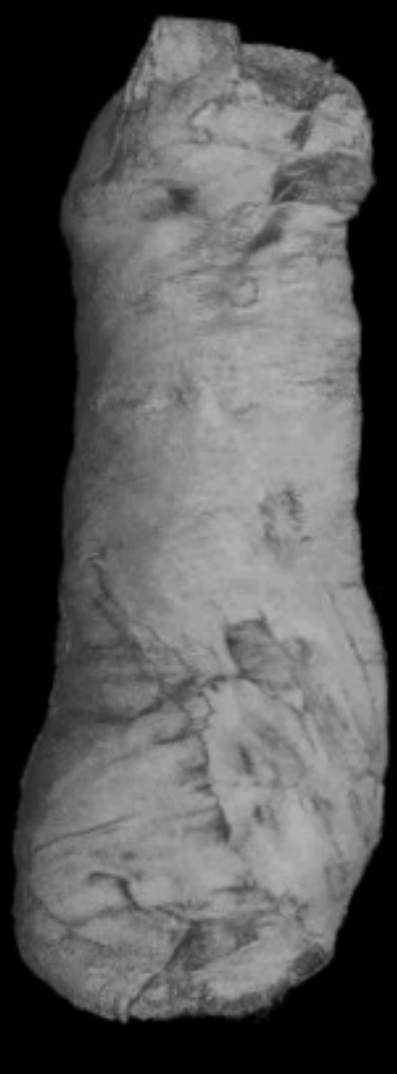

d)
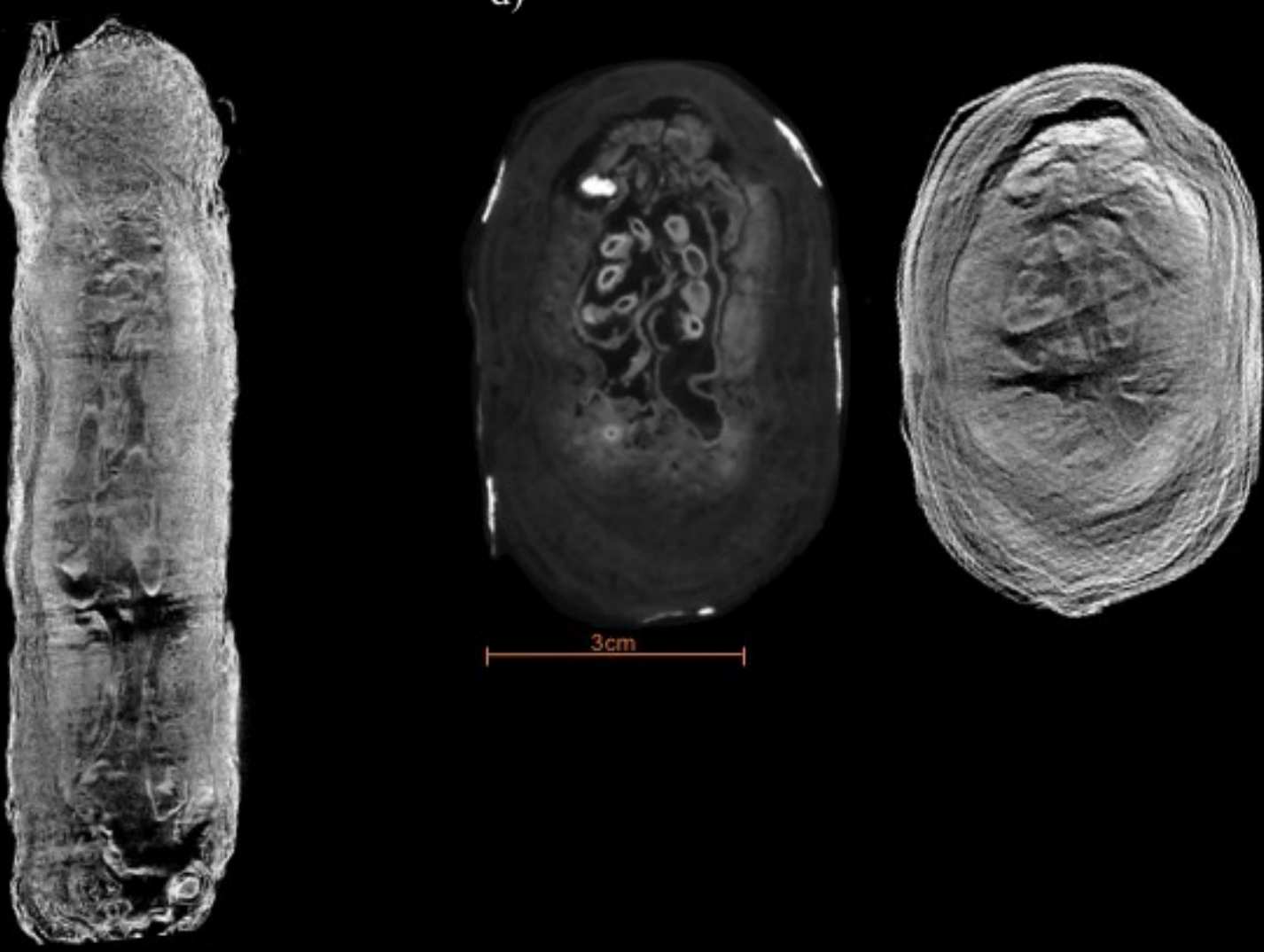

ARCM_12477_Figure_4.jpg

This article is protected by copyright. All rights reserved. 

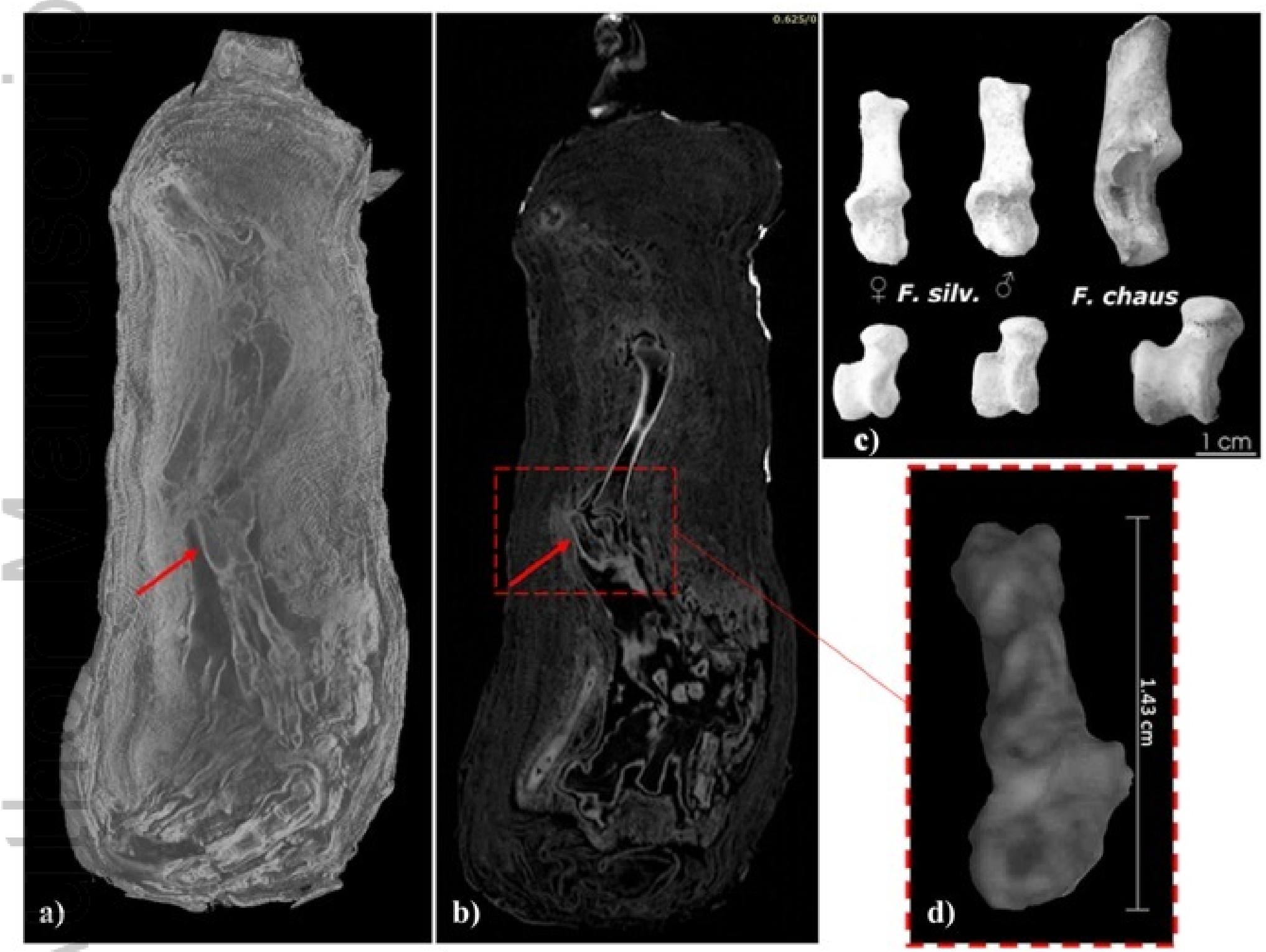

ARCM_12477_Figure_5.jpg 


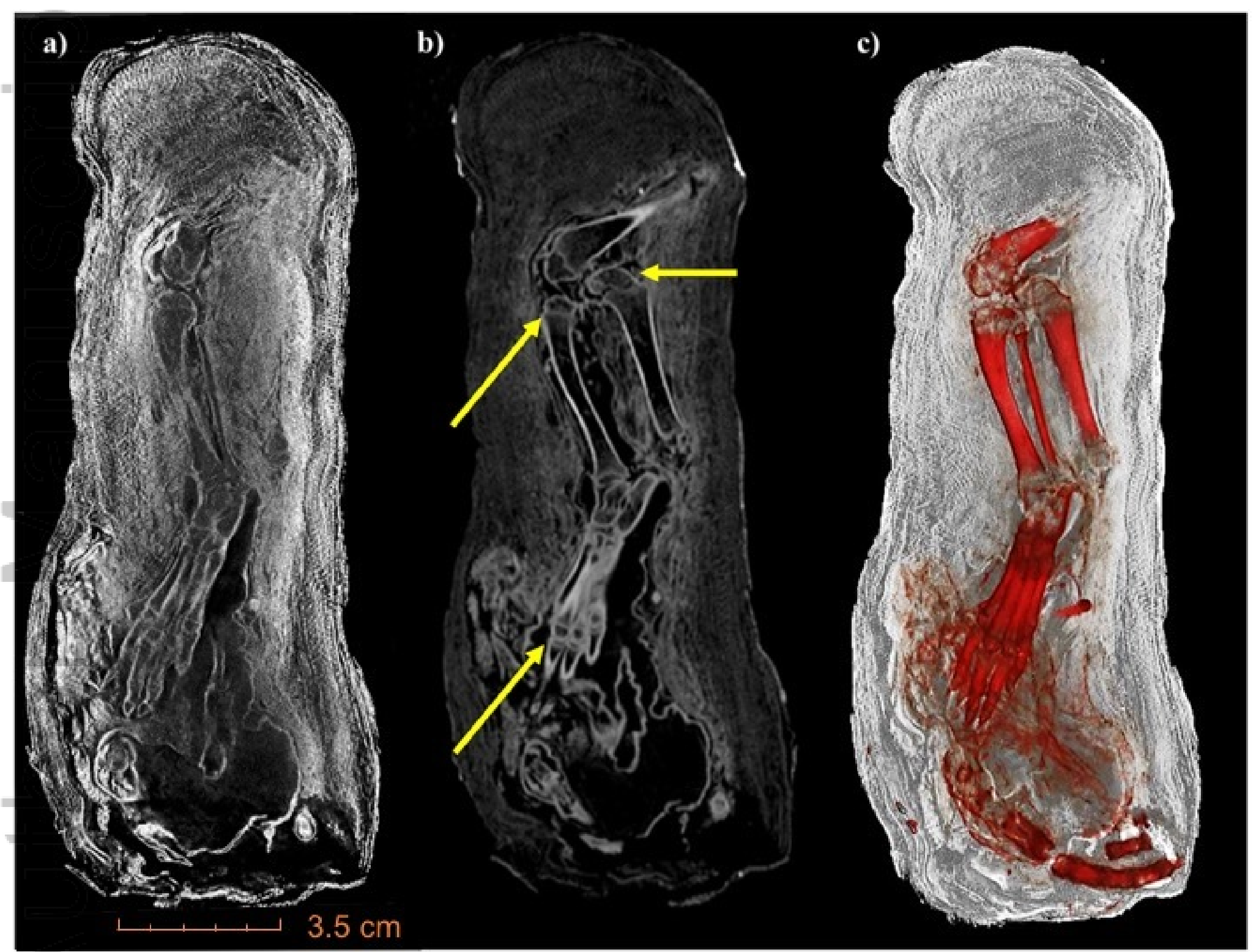

ARCM_12477_Figure_6.jpg 


\section{University Library}

\section{- M M I N E R VA \\ A gateway to Melbourne's research publications}

Minerva Access is the Institutional Repository of The University of Melbourne

Author/s:

Raymond, CA;Bevitt, JJ;Tristant, Y;Power, RK;Lanati, AW;Davey, CJ;Magnussen, JS;Clark, SM

Title:

Recycled Blessings: An Investigative Case Study of a Rewrapped Egyptian Votive Mummy Using Novel and Established 3D Imaging Techniques

Date:

2019-10-01

Citation:

Raymond, C. A., Bevitt, J. J., Tristant, Y., Power, R. K., Lanati, A. W., Davey, C. J., Magnussen, J. S. \& Clark, S. M. (2019). Recycled Blessings: An Investigative Case

Study of a Rewrapped Egyptian Votive Mummy Using Novel and Established 3D Imaging Techniques. ARCHAEOMETRY, 61 (5), pp.1160-1174. https://doi.org/10.1111/arcm.12477.

Persistent Link:

http://hdl.handle.net/11343/286870 